OKADA, S. \& O'BRIEN, J.S. (1968) Generalised gangliosidosis; $\beta$-galactosidase deficiency. Science, Washington, 160, 1002.

SACrez, R., Juif, J.G., Gigonnet, J.M. \& Gruner, J.E. (1967) La maladie de Landing, ou idiotie amaurotique infantile précoce avec gangliosidose généralisée de type $\mathrm{GM}_{1}$. Journée de Pédiatrie, 22, 143.

ScotT, C.R., LAGUNOFF, D. \& TrumP, B.F. (1967) Familial neurovisceral lipidosis. Journal of Pediatrics, 71, 357.

Seringe, P., Plainfosse, B., Lautmann, F., Lorilloux, J., Calamy, G., Berry, J.P. \& Watchi, J.M. (1968) Gangliosidose généralisée du type Norman-Landing, à $\mathbf{G M}_{\mathbf{1}}$. Annales de Pédiatrie, 15, 165.

Singer, H.S., NANkervis, G.A. \& Schafer, I.A. (1972)
Leucocyte beta-galactosidase activity in the diagnosis of generalised GM 1 gangliosidosis. Pediatrics, 49, 352.

Suzuki, K., SuzuKI, K. \& Kamoshita, S. (1969) Chemical pathology of $\mathbf{G M}_{1}$-gangliosidosis (generalised gangliosidosis). Journal of Neuropathology and Experimental Neurology, 28, 125.

TANNeR, J.M., Whitehouse, R.H. \& Takaishi, M. (1966) Standards from birth to maturity for height, weight, height velocity, weight velocity: British children, 1965-Part II. Archives of Disease in Childhood, 41, 613.

Young, E., Ellis, R.B. \& Patrick, A.D. (1972) Leucocyte $\beta$-galactosidase activity in $\mathbf{G M}_{1}$ gangliosidosis. Pediatrics, 50, 502.

\title{
Acute rheumatic fever following streptococcal wound infection
}

\author{
K. D. Popat* \\ M.B.B.S.
}

\author{
W. D. RIDING \\ M.A., M.B., M.R.C.P.
}

\section{Bedford General Hospital, Bedford}

\section{Summary}

A case of acute rheumatic fever with pancarditis secondary to infection of abrasions on the hand with Bhaemolytic streptococci is described.

\section{Introduction}

Despite the decline in recent years in the incidence of rheumatic fever, interest in the disease is unabated because of its unique relationship to streptococcal infections. Epidemiological evidence suggests that rheumatic fever occurs only after streptococcal pharyngitis, but not in association with streptococcal skin infections such as impetigo.

The purpose of this paper is to describe a patient who developed acute rheumatic fever following infection of abrasions, and to draw attention to the possible danger of acute rheumatic fever in meat handlers who are liable to develop streptococcal infection of cuts on the hand.

\section{Case report}

A 17-year-old butcher was admitted to Bedford General Hospital with a history of fever and

Requests for reprints: Dr K. D. Popat, Department of Cardiology, Harefield Hospital, Harefield, Middlesex. generalized joint pains. Between 2 and 3 weeks earlier he had sustained small cuts on both hands at work. These cuts had become infected and had failed to heal. Five days before admission he developed a fever and left shoulder pain. The following day he had pain and stiffness in both knees, ankles and feet, and 2 days later sharp stabbing retrosternal pain aggravated by movement, deep inspiration and coughing. There was no family or past history of rheumatic fever.

On admission, he was flushed and pyrexial with rapid shallow breathing. There was a single infected abrasion on the extensor surface of each hand. Pulse regular-110/min. Blood pressure-140/90. Apex beat was displaced outside the left mid-clavicular line. Heart sounds normal. Loud pericardial friction rub audible over the praecordium. The jugular venous pressure was raised to $4 \mathrm{~cm}$ with patient erect. Movement of shoulders, knees, elbows, wrists, fingers and toes was painful and restricted. There was no abnormality in the respiratory, alimentary or nervous systems.

Investigations. Haemoglobin $13.6 \mathrm{~g} / 100 \mathrm{ml}$. White Cell Count 7,200/ $\mathrm{mm}^{3}$. ESR $75 \mathrm{~mm} / \mathrm{hr}$ (Westergren). ASO titre 500 Todd units. Throat swab 


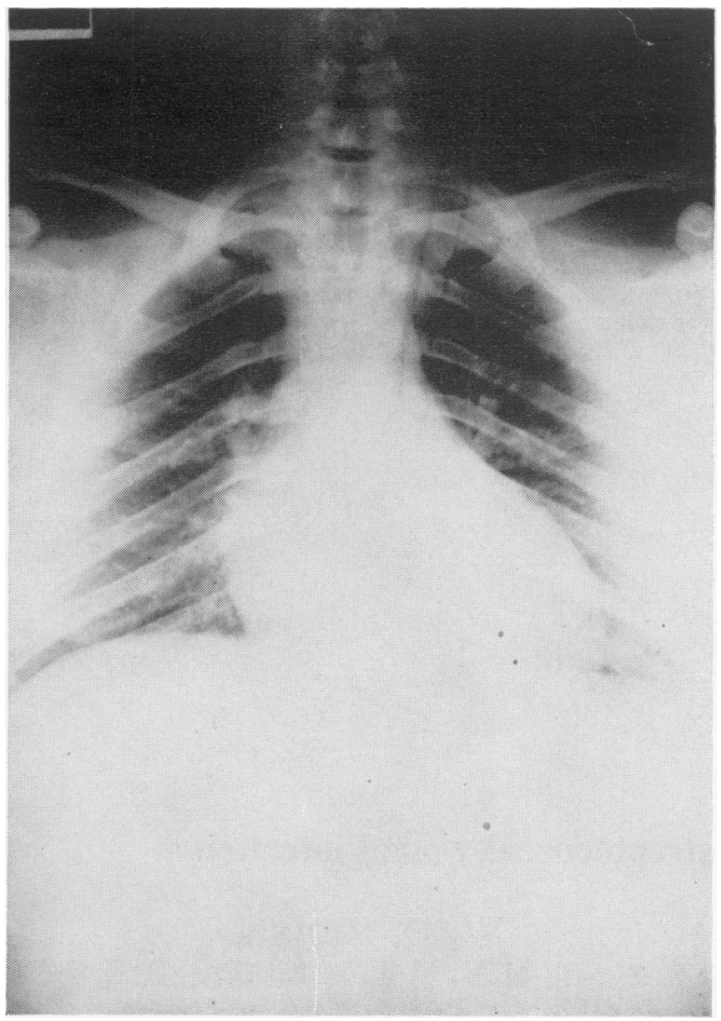

FIG. 1. Chest $X$-ray taken on admission (3.12.74) showing cardiac enlargement. cultured no pathogens and, in particular no haemolytic streptococci. Swabs from both hand abrasions grew $\beta$-haemolytic streptococci Lancefield Group A type T 3/B3264/13 and M-negative. Chest X-ray showed cardiac enlargement (Fig. 1). Electrocardiogram showed sinus rhythm, PR interval 0.12 sec and widespread elevation of the RS-T segment typical of pericarditis (Fig. 2).

He was nursed in an armchair for comfort and given soluble aspirin $\mathbf{3} \mathrm{g}$ daily in divided doses, and benzyl penicillin $1 \mathrm{Mu}$ twice daily. The joint pains and stiffness improved within a few days of treatment and completely subsided by the end of the second week in hospital. Pyrexia rapidly settled (Fig. 3). Six days after admission be became more breathless and developed pulsus paradoxus and gross elevation of the jugular venous pressure. The apex beat was palpable in the left anterior axillary line. Chest X-ray showed a marked increase in cardiac size (Fig. 4). He was treated with bendrofluazide and, after a marked diuresis, breathlessness and clinical signs of pericardial tamponade resolved. Chest Xray showed a reduction in cardiac size (Fig. 5). Pericardial rub settled during the third week and ECG at this time showed a reduction in ST elevation and inversion of $T$ waves (Fig. 6). His subsequent progress was uneventful although a soft systoê lic murmur was audible at the apex for several days in the fourth week. ASO titre rose to 1,000 Todक units 1 month after admission while ESR felf progressively to normal by the end of the fifth week. Penicillin-V $250 \mathrm{mg}$ orally 6-hourly was substituted

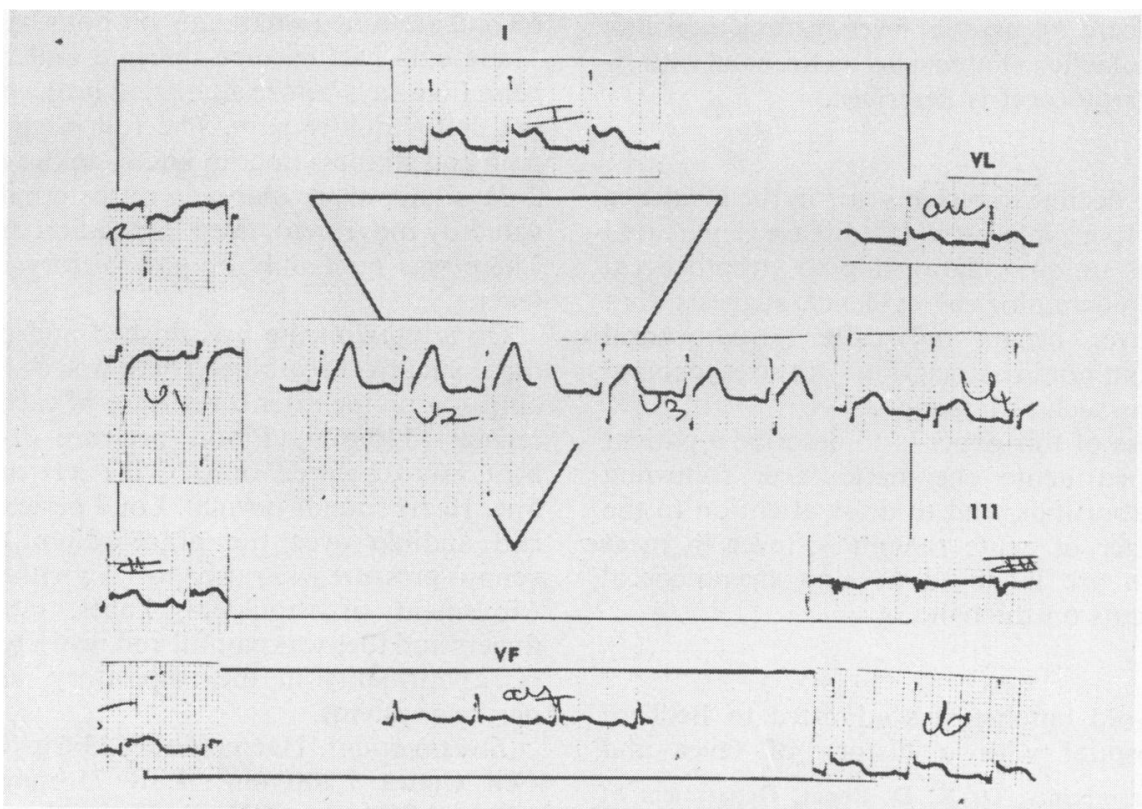

FIG. 2. ECG tracing on admission showing sinus rhythm, and widespread elevation of the RS-T segment. 

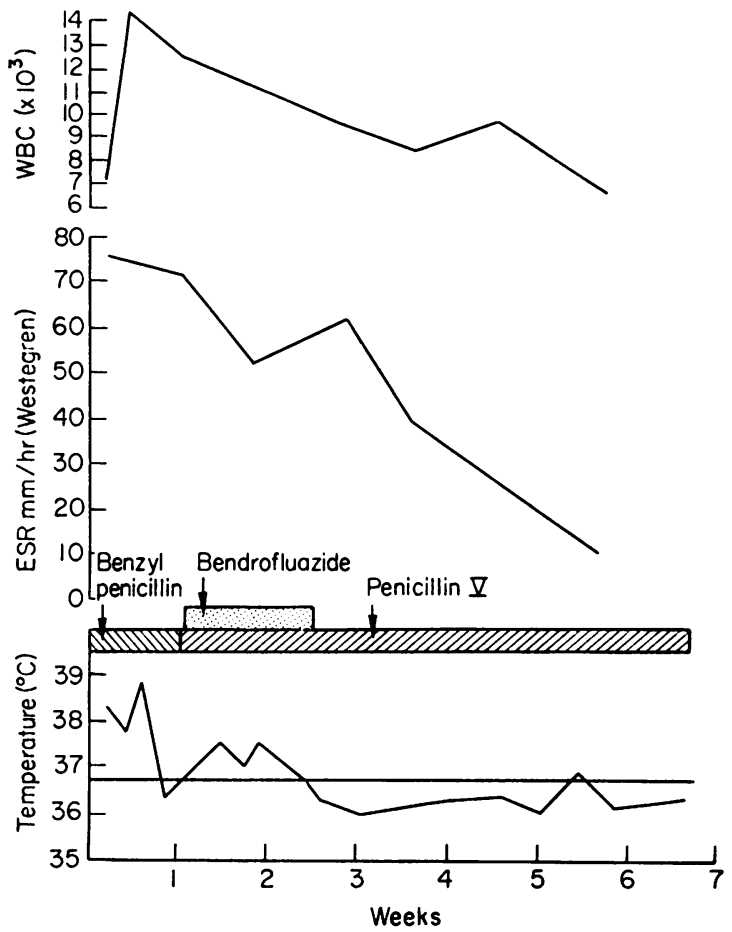

FIG. 3. Diagram showing improvement in the patient's progress.

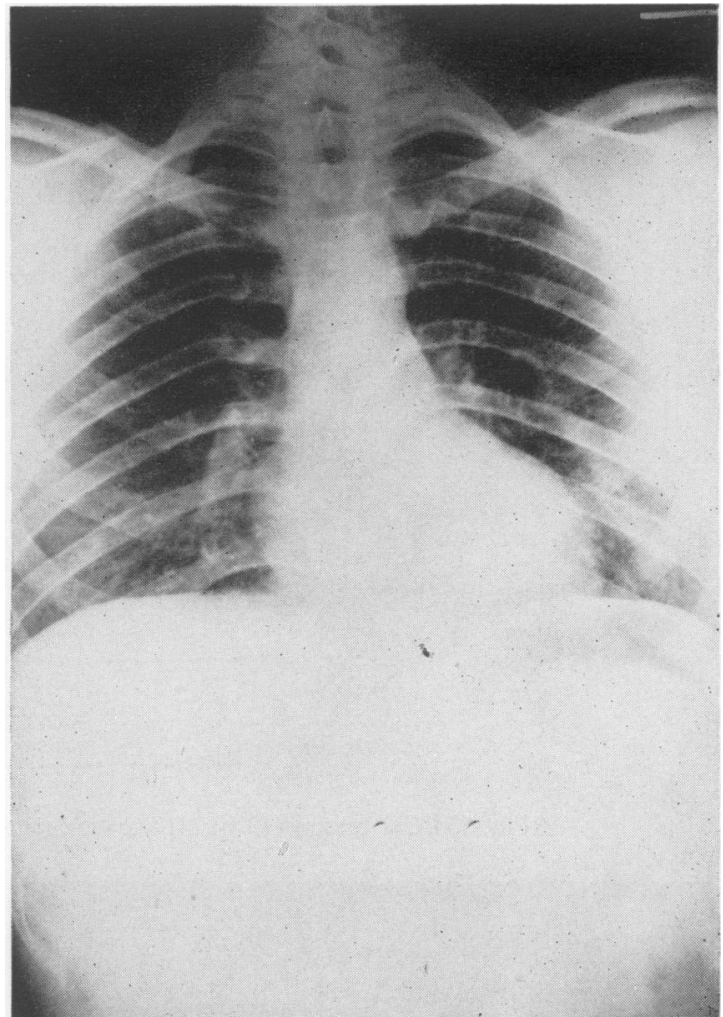

FIG. 5. Chest $\mathrm{X}$-ray showing reduction in cardiac size following diuretic therapy.

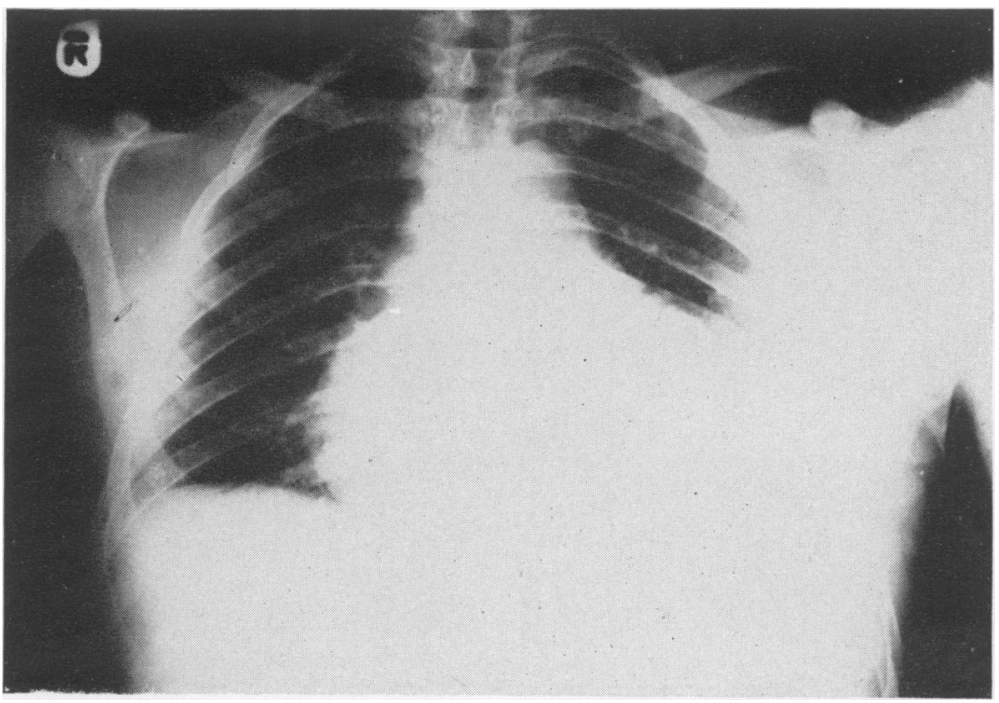

FIG. 4. Chest $X$-ray $(10.12 .74)$ showing the marked increase in cardiac size. 


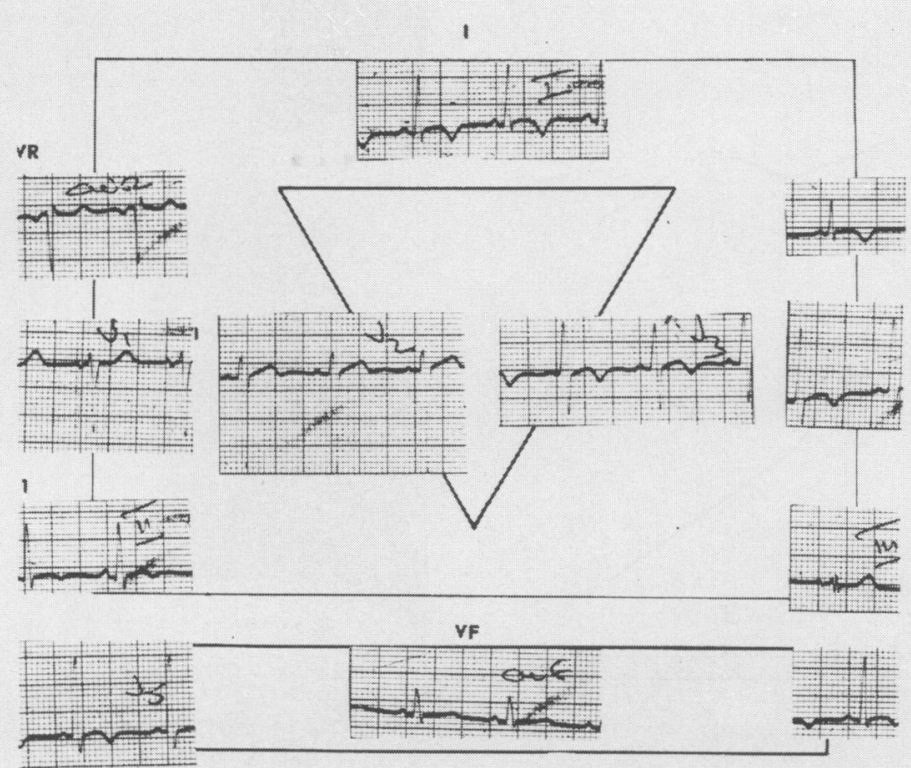

FIG. 6. ECG tracing (19.12.74) showing reduction in ST elevation and inversion of $T$ waves.

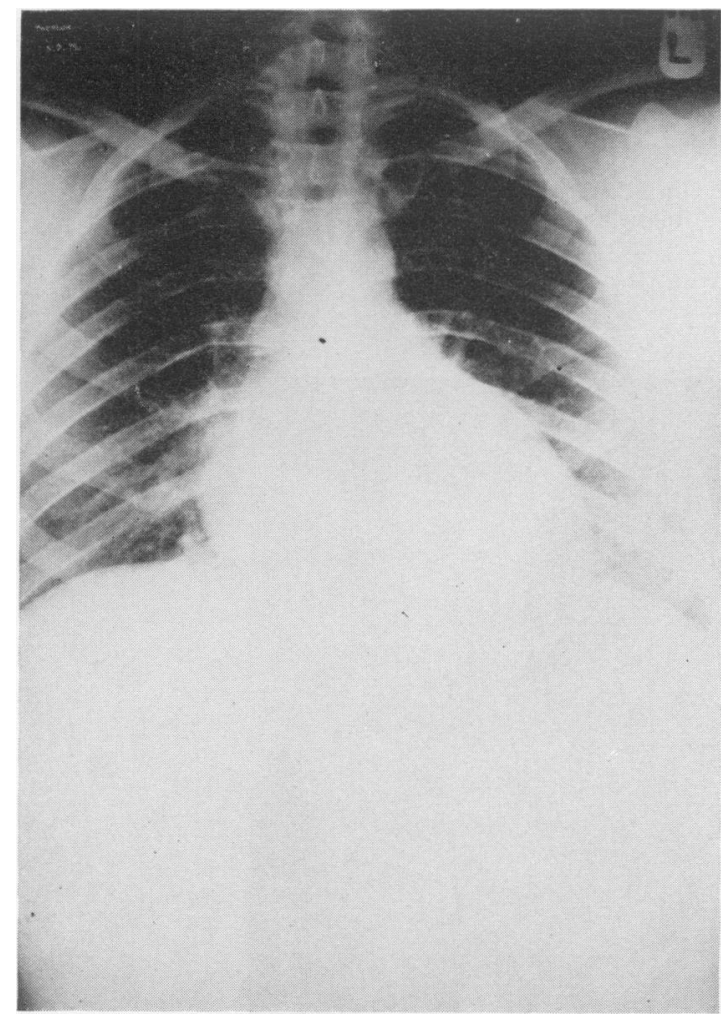

FIG. 7. Chest X-ray (6.2.75) showing increase in the transverse diameter of the heart and pulmonary congestion.

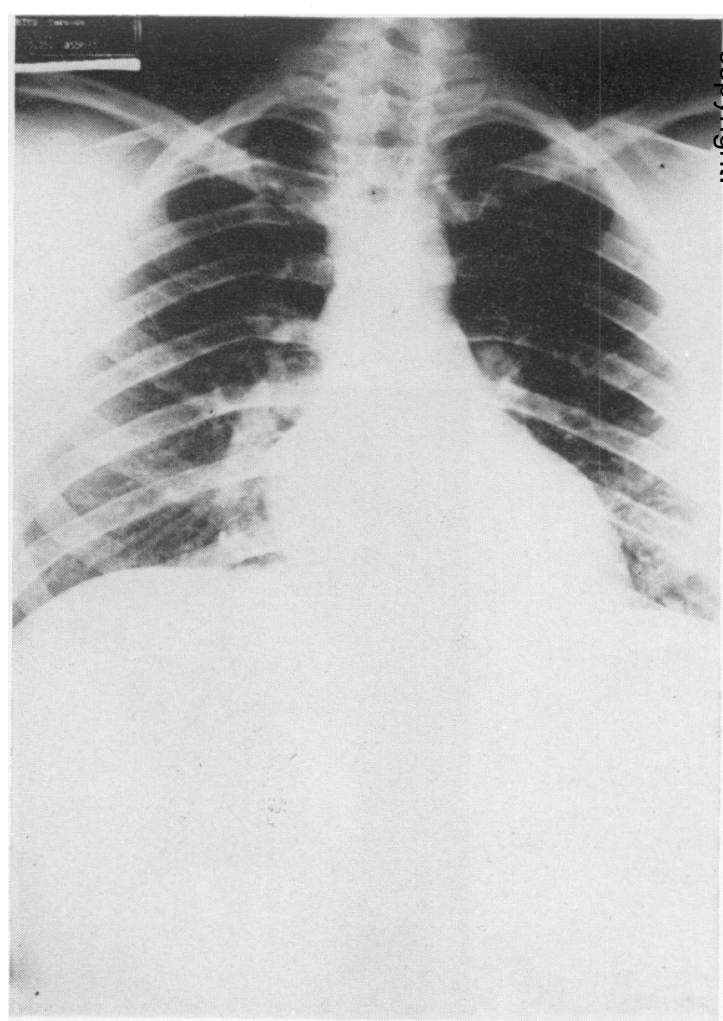

FIG. 8. Chest X-ray (11.3.75) showing normal cardiac size and clear lung fields. 


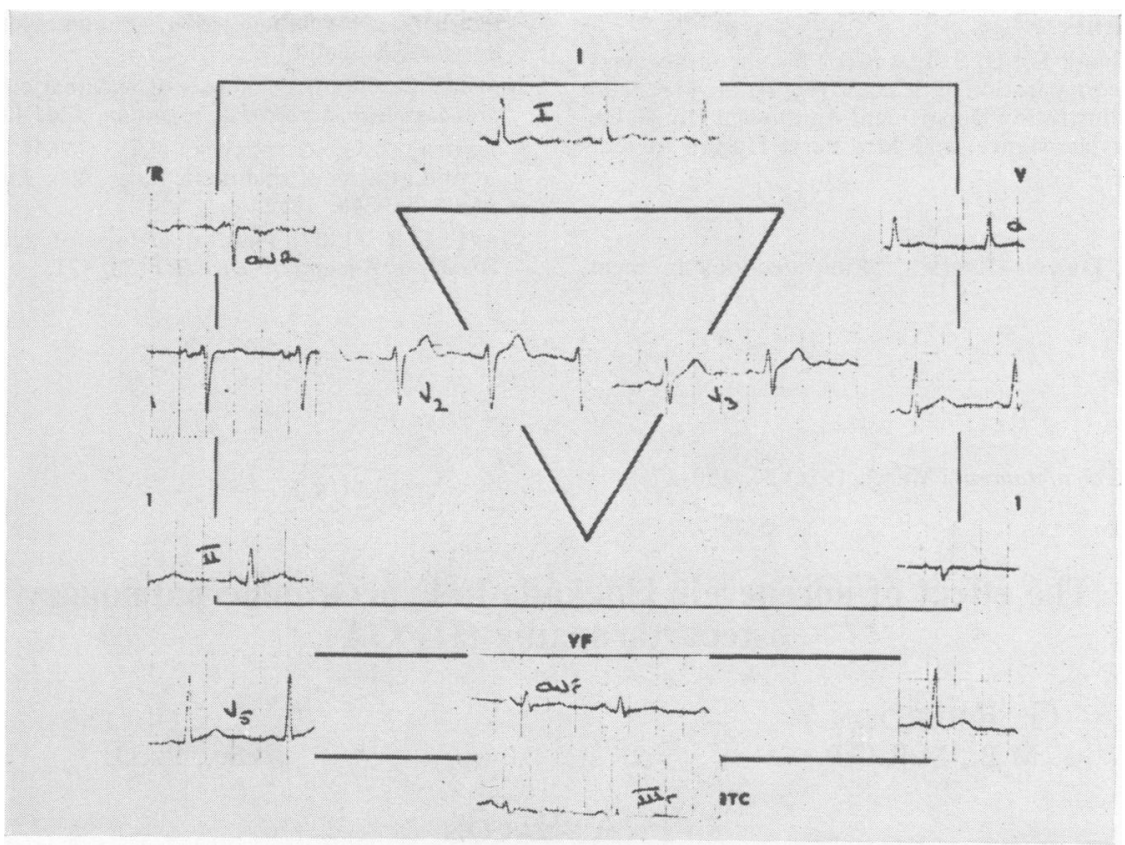

FIG. 9. ECG (11.3.75) normal.

for benzyl penicillin from the sixth day and reduced to $250 \mathrm{mg}$ b.d. at the time of his discharge from hospital. Soluble aspirin was gradually reduced from the fourth week and was discontinued soon after discharge.

However, when seen as an out-patient 4 weeks after discharge, he complained of exertional breathlessness and bilateral shoulder pain for 1 week. Chest X-ray showed an increase in the transverse diameter of the heart and pulmonary congestion (Fig. 7), while ESR had risen to $85 \mathrm{~mm} / \mathrm{hr}$. Diuretics and rest were prescribed. Two weeks later he was free from breathlessness and pain and ESR had fallen to $2 \mathrm{~mm} / \mathrm{hr}$. Chest X-ray showed reduction in the transverse diameter of the heart and clear lung fields (Fig. 8), and ECG was normal (Fig. 9). Thereafter, he remained well.

\section{Discussion}

The association of rheumatic fever with streptococcal pharyngitis and tonsillitis is well recognized. Surprisingly, there appears to be no reported association between rheumatic fever and streptococcal skin infection. This patient, however, developed acute rheumatic fever following streptococcal infection of abrasions on the hands. The diagnosis of acute rheumatic fever was definite as he had two major and three minor manifestations according to the criteria of Jones (1944). $\beta$-haemolytic streptococci were isolated from both skin abrasions but not from the throat swab.

A recent report (Communicable Disease Report, November, 1974) recounts several outbreaks of streptococcal and staphylococcal wound infections in meat handlers at Peterborough, Nottingham and Shrewsbury. It has been suggested that the outbreaks occur because small cuts and scratches on the hands and wrists are common in abattoir workers and because animal carcasses harbour $\beta$-haemolytic streptococci.

It is considered on the evidence presented that meat handlers are at risk of developing acute rheumatic fever following infection of the small cuts on the hand with $\beta$-haemolytic streptococci. The possibility of acute rheumatic fever should, therefore, be considered when treating simple infected cuts in meat handlers. The patient, who is keen to continue working as a butcher, will be maintained on penicillin-V $250 \mathrm{mg}$ b.d. indefinitely because of the risk of recurrent skin infection with $\beta$-haemolytic streptococci and, therefore, a greater liability to rheumatic carditis.

Kuttner and Mayer (1963) found that up to $60 \%$ of patients with rheumatic carditis re-developed it in subsequent attacks with more severe valve damage. Anti-streptococcal antibiotics given prophylactically greatly reduce the frequency of recurrent attacks of rheumatic fever (Perry, 1969). 


\section{Acknowledgments}

We wish to thank Dr D. S. Lewes for his encouragement and advice in the preparation of this case report, $\mathrm{Mr}$ Morrison of the Medical Illustration Department, Luton and Dunstable Hospital, for his assistance, and Mrs Beryl Hutton for her secretarial work.

\section{References}

Communicable Disease Report. Skin infections in meat handlers. November, 1974, Public Heath Laboratory Services, England.

JoNES, T.D. (1944) Diagnosis of rheumatic fever. Journal of the American Medical Association, 126, 481.

Kuttner, A.G. \& MAyer, F.E. (1963) Carditis during second attacks of rheumatic fever. New England Journal of Medicine, 268, 1259.

Perry, C.B. (1969) Natural history of acute rheumatism. Annals of Rheumatic Diseases, 28, 471.

\title{
The effect of adrenergic blockade in hypertrophic pulmonary osteoarthropathy (HPOA)
}

\author{
G. REARDON * \\ M.B., M.R.C.P.
}

A. J. Collins

B.Sc., Ph.D.

\author{
P. A. BACON \\ M.B., M.R.C.P. \\ Royal National Hospital for Rheumatic Diseases, Bath
}

\section{Summary}

A case of hypertrophic pulmonary osteoarthropathy (HPOA) is described, together with synovial fluid cytology and synovial histology. A new approach to therapy is described using adrenergic blockade. The effectiveness of this regime was assessed by quantitative thermography. The successful results support the neurogenic hypothesis for the aetiology of HPOA.

\section{Introduction}

Hypertrophic osteoarthropathy was described over 80 years ago (Bamberger, 1889; Marie, 1890). There have been several series and case reports published since, but the aetiology remains obscure. Furthermore, therapy aside from treatment of the primary lesion is usually disappointing. A case is presented of hypertrophic osteoarthropathy, secondary to carcinoma of the lung, with obiective assessment by quantitative thermography. This was used to demonstrate diminution in limb hypervascularity when treatment by sympathetic blockade was initiated. Synovial fluid and histology findings are also reported.

\footnotetext{
* Present address: Rheumatism Research Unit, Stoke Mandeville Hospital, Aylesbury, Bucks.

Reprint requests: Dr P. A. Bacon, Royal National Hospital for Rheumatic Diseases, Upper Borough Walls, Bath BA1 1RL.
}

\section{Case report}

A 63-year-old female, a chronic cigarette smoker, presented with a 10-month history of painful swelling of both legs and arms, with accompanying morning stiffness. She had initially been treated as a case of probable rheumatoid arthritis, with non-steroidal anti-inflammatory agents and, more recently, with weekly injections of $1 \mathrm{mg}$ tetracosactide (synacthen; Ciba). Following injection she symptomatically and objectively improved for 2 days, with almost com plete disappearance of joint swelling, followed by relapse to the previous state.

Examination revealed small effusions in both knee joints, and swelling in the metatarsophalangeal and proximal interphalangeal joints of both hands. In addition there was marked tenderness and local warmth along the shin and forearm, particularly near the joints, together with gross clubbing of the fingers and toes. Other examination, including that of the respiratory system, revealed no abnormality. X-rays of her chest revealed a localized opacity near the hilum of the right lung. Peripheral films demon. strated extensive characteristic periostitis of hypertrophic osteoarthropathy, most marked near the diaphysis, but involving the entire length of the long bones of the upper and lower limbs.

A right lower lobectomy was performed revealing a well defined neoplasm with an anaplastic small cell 